\title{
Relay Protection of Transmission Line in the Micro-Grid Based on Frequency Modulation
}

\author{
Yifei Xu, Huan Ma, Jiao He, and Dehua Zhang
}

\begin{abstract}
In recent years, the development of the micro-grid technology is promoted rapidly. In this paper, considering the fault characteristics of the micro-grid and the insufficiency of micro-grid relay protection, relay protection of transmission line applied in the micro-grid based on frequency modulation is proposed firstly. Then, differences between the micro-grid relay protection and the traditional one are introduced. After that, the operational principle and the whole working process of the frequency modulation are analyzed. Finally, by simulation and experiments, the novel proposed frequency modulation method is proved correct and practical.
\end{abstract}

Index Terms-Micro-grid, inverter, frequency modulation, relay protection, frequency conversion.

\section{INTRODUCTION}

As known, the distributed power generation technology taking advantage of local renewable energy not only can reduce reserve capacity of the power grid and increase the reliability of power supply but can reduce environmental pollution and alleviate the energy crisis. Based on characteristics of the distributed power supply, when the fault occurs in the power grid, the power grid will produce flow effect if distributed power supply is not disconnected timely. However, if it is disconnected timely, operation and control of the power grid will become difficult. Because of this, distributed power supply cannot be well used in power grid. The researchers put forward the concept of micro power grid that can solve the problem of distributed power grid in recent years.

The micro-grid, as an autonomous network system, is composed of a variety of distributed power supply, the energy storage component unit, monitoring and protection device. Through the Point of Common Coupling (PCC), it is connected with low or medium voltage distribution network. It has two running modes, parallel operation and islanded operation.

At present, the study on relay protection of the micro-grid has just started, there is still no suitable and practical protection scheme. Some researchers put forward that fault location and isolation need enough fault current information provided by distribution network [1]-[4]. Someone thinks the DG terminal voltage THD (Total

Manuscript received October 8, 2014; revised March 29, 2015. This paper is funded by the national natural science funds No: 51107117

Yifei Xu, Jiao He, and Dehua Zhang are with the College of Electrical Engineering, Zhejiang University, China, CO 310013 CHN, China (e-mail: xyflxnh@163.com).

Huan Ma is with the East China Tongbai Pumped Storage Power Co. Ltd., State Grid Xinyuan Company, China, CO 310003 CHN, China (e-mail: xyflxnh@163.com).
Harmonic Distortion) can also judge the fault position [5]. The paper [6]-[8] presents signal differential system protection. According to the characteristics of the micro-grid [9]-[11], formulating the related control method and protection scheme is meaningful for the large-scale application of distributed generation technology.

\section{The Analysis of the FAult Characteristics IN ThE MICRO-GRID}

The micro-grid is usually a three-phase four-wire neutral-ground system. Because the numerous interior contact-line and feeder-line and diverse types of the load, the micro-grid is prone to short circuit, overload, over-voltage fault and so on.

If fault occurs, the micro-grid is divorced from the grid. As the short circuit capacity of distribution network is not enough and inverter power supply capacity is relatively small, the internal fault current is very small in the micro-grid. At the same time, there are a large number of distributed power which is close to each other in the micro-grid. Relay protection for the micro-grid is different from the traditional power grid.

When fault occurs in the micro-grid, it will have an impact on the protection of distribution network such as bidirectional power flow and current effect.

\section{A. Bidirectional Power Flow}

In the micro-grid, distributed power supply may access to both sides of the transmission line. Then, the power flow will be two-way. As shown in Fig. 1, if a fault occurs at K, DG2 will provide short-circuit current to the fault point under the condition of the same capacity. Reverse fault current flows through R2 and R3. Supposing that the current is large enough, R2 and R3 will be error operation.

\section{B. Current Effect}

In the distribution network, it is single supply at power supply side while it is multiple-feed at one side in the micro-grid [12]. All power supply will inject fault current to the fault point in case of the short-circuit fault, which makes fault current larger. So, selectivity of relay protection is bound to be influenced. On the other hand, due to shunting effect of the multiple-feed, the fault current will be very low at front end. So, sensitivity of relay protection is bound to be influenced as well. As shown in the figure below, the occurrence of short circuit at $\mathrm{K} 2$ makes that power generation DG1 and DG2 inject fault current to the point K2. Large current at K2 leads R4 or R5 to be malfunction. At the same time, fault current at R2 and R3 gets smaller. R2 and R3 will not act. 


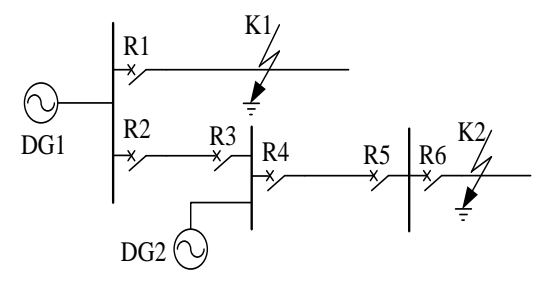

Fig. 1. The fault characteristics of the micro-grid.

\section{The Theoretical Basise of Relay PRotection BASED ON FREQUENCY MODULATION}

\section{A. The Principle of the Proposed Relay Protection}

In essence, relay protection based on frequency modulation puts the current induced increment in the failure case to the frequency modulation. If so, inverter power supply can output fault information without over-limit. Through demodulation of the protection device, virtual short circuit current can be regained. This value is close to the short circuit current value of rotating electrical machines in case of the same line impedance. As a result, we can analogy to traditional over current protection relay protection. Not only that, the virtual short circuit voltage can be known according to the value of virtual short circuit current. Low voltage protection works.

As shown in Fig. 2, once inverters reach the output limit value, the output value will not change any more. The frequency modulation reflects the line impedance. Then, virtual short circuit current can be known based on sampling frequency value. Its frequency value is $50 \mathrm{~Hz}$ and its amplitude reflects the line impedance as the dotted line shown in the figure below.

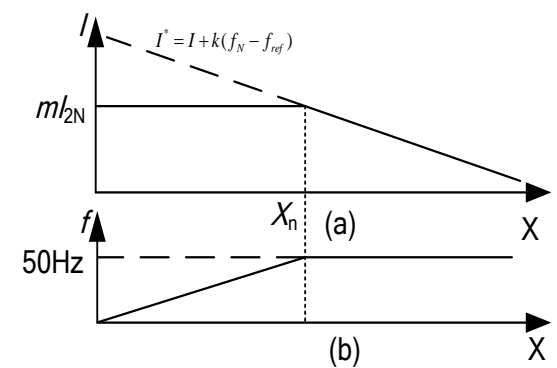

Fig. 2. The principle of frequency conversion control.

This paper is based on several assumptions as follows: the output phase voltage value of rotary motor is a constant; the maximum output value of inverter power supply is $\mathrm{m}$ times rated current value and $\mathrm{m}$ is between 1.5 and 2 .

\section{B. Modulation of Virtual Short Circuit Current}

When the fault occurred, the maximum output current of the inverter is restricted to two times rated current so we assume that the aptitude of output current $\mathrm{I}_{\text {refm }}$ is equal to $\mathrm{mI}_{\mathrm{N}}$.

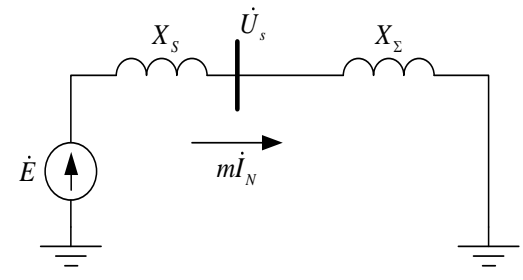

Fig. 3. The equivalent circuit diagram.
The line impedance can be expressed as:

$$
X=X_{S}+X_{\Sigma}=X_{S}+\frac{\dot{U}_{S}}{m \dot{I}_{N}} \approx X_{S}+\frac{U_{m}}{m I_{N}}
$$

where $U_{m}$ is the aptitude of voltage detected at the output port, $X_{S}$ is the intrinsic impedance of electrical source and $X_{\Sigma}$ is the line impedance.

After reduction, virtual short circuit current can be derived as follows:

$$
I^{*}=\frac{\dot{E}}{\dot{X}_{S}+\dot{X}_{\Sigma}} \approx \frac{E}{X_{S}+X_{\Sigma}}=\frac{E}{X_{S}+\frac{U_{m}}{m I_{N}}}
$$

where

$\dot{E}$ is the rated-output Phase-voltage of rotating machine.

Relationship of virtual short circuit current and the reference frequency is given by:

$$
I^{*}=m I_{N}+k\left(f_{N}-f_{r e f}\right)
$$

where

$f_{N}$ is the rated frequency of current and $\mathrm{k}$ is the modulation factor of frequency conversion.

In conclusion, frequency-conversion modulation could be construed as: $I^{*}$ is compared with the actual current by hysteresis loop. Then the turn-on pulse is produced. As the voltage source convert achieve the pulse, we can detect the current that its aptitude is $2 I_{N}$ and its frequency is changeable. Through calculation, we can know the current with the frequency of $50 \mathrm{~Hz}$. Thus by the traditional current protection of power grid, the transmission line protection for micro grid is attainable.

\section{Demodulation of Virtual Short Circuit Current}

As mentioned above, after modulation, the aptitude of current detected is fixed and the frequency is not $50 \mathrm{~Hz}$. Supposing that the frequency of the current is $\mathrm{f}$, the aptitude is $\mathrm{I}_{\mathrm{m}}$. According to the formula, the current can be converted into three-phase short-circuit current of electrical machinery. Then traditional three-section current protection can be used as follow:

$$
I^{*}=I_{N}+k\left(f_{N}-f\right)
$$

According to previous analysis, when faults occur, voltage and frequency in the micro-grid will exceed the limitation. If $\mathrm{V} / \mathrm{f}$ control method is still used, the transmission line impedance is going to reduce and the current is going to increase greatly. If PQ control method is used, the current is going to increase greatly as well since the voltage collapses. Therefore, control method in fault condition should be changed to ensure output current not to exceed the limit. But if we just limit the output aptitude of Inverter power supply, the selectivity requirement of output current is unable to be met.

Inverter power supply do not have the mechanical inertia compared with rotating machine power supply. It responses quickly so the output value could be changed as soon as the fault occurs. Because of the Specificity of frequency, fault information can be easily achieved and Implementation of relay protection becomes possible. 


\section{Simulation AND EXPERIMENTS OF THE PROPOSED RELAY PROTECTION}

\section{A. The Design of the Inverter-Power-Source Controller}

Internal wiring of wiring way in the micro-grid have three kinds: emanate supply type, two-end supply type and ring supply type. For Study on The applicability and rationality of the control strategy after the fault, single-end supply type is used in the simulation.

The output voltage and current can be detected by the voltage transformer and current transformer respectively. The reference virtual short-circuit current of frequency conversion will be produced by short circuit current modulation based on the reference voltage and control signal. The variable frequency control module of VSC generates a control pulse by hysteresis control according to the reference current and the measured current $\dot{I}$. The pulse can control the switch of the VSC. Then, current at $\mathrm{DC}$ side can be converted into current at $\mathrm{AC}$ side. In addition, the aptitude of the output short-circuit current of inverter power supply is fixed and the frequency is variable.

\section{B. The Analysis of the Simulation and Experiments}

We can assume: output voltage of rotary motor power maintains $310 \mathrm{~V}$; when no failure occurs, voltage hysteresis control can ensure that the output port of the phase voltage is $220 \mathrm{~V}$. After the three-phase short circuit fault occurs, current hysteresis control can ensure the aptitude of output current is 20A. Then, the output of the inverter will not exceed the limits. The experimental results consist with our hypothesis.

As can be seen from Fig. 4 and Fig. 5, when there is no fault, the aptitude of output current is 20A. Also, the output phase voltage of inverter power supply maintains $220 \mathrm{~V}$ and its frequency is $50 \mathrm{~Hz}$ as expected. After the three-phase short circuit fault occurs, for making sure that the output of the inverter will not exceed the limits, voltage drops significantly as the line impedance decreases. According to the obtained modulation function, we can know the frequency is about $45 \mathrm{~Hz}$.

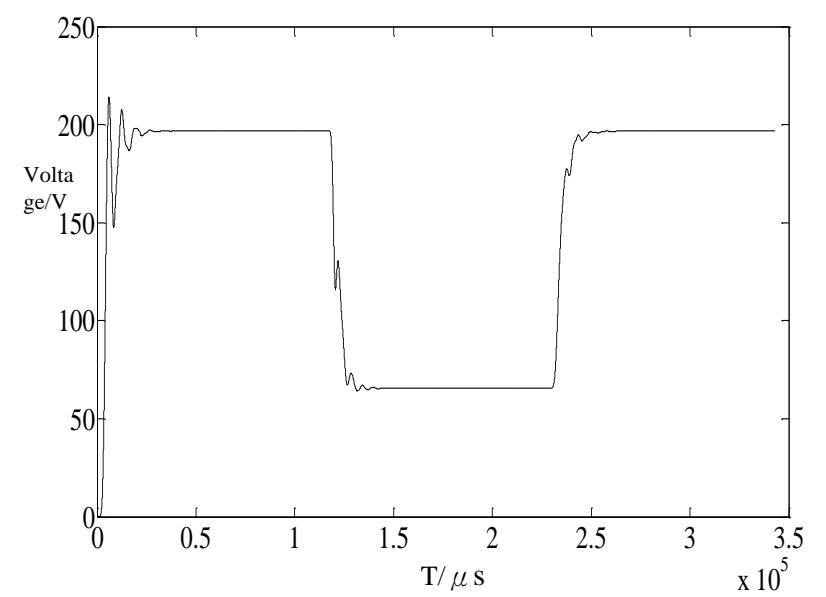

Fig. 4. The output voltage of inverter power supply.

As can be seen from the figure above, current frequency is within $35 \mathrm{~Hz}$ when no fault occurs but when the three-phase short-circuit fault occurs, the frequency drops to about $10 \mathrm{~Hz}$. This process reflects that the output aptitude becomes constant and frequency becomes variable in the use of frequency conversion control. Through the virtual short circuit current demodulation process of the next, the frequency of the output current is constant and aptitude is large. The simulation process reflects the fault characteristics of the inverter power supply.

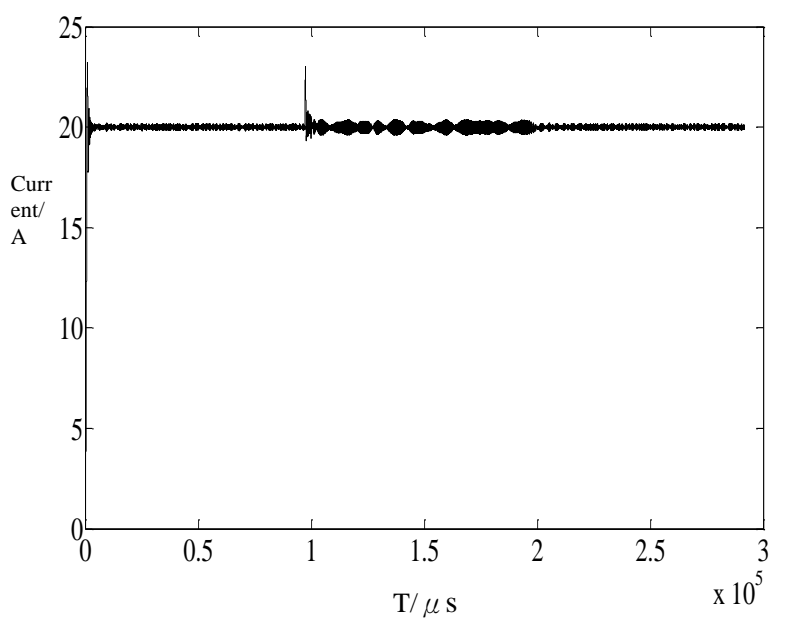

Fig. 5. The output current of inverter power supply.

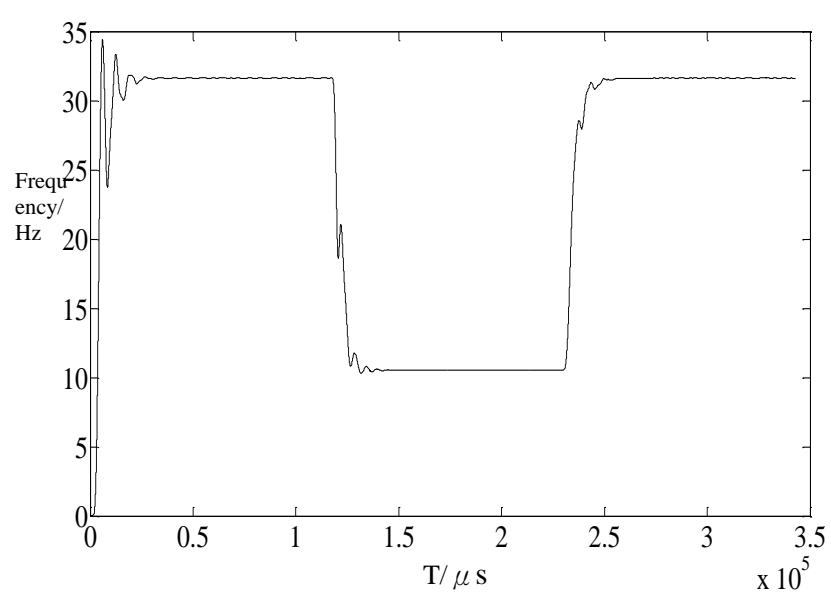

Fig. 6. The frequency of output current.

The comparison chart of virtual short-circuit current and rotating machine short circuit current can be shown in Fig. 7. The current is nearly the same as expected.

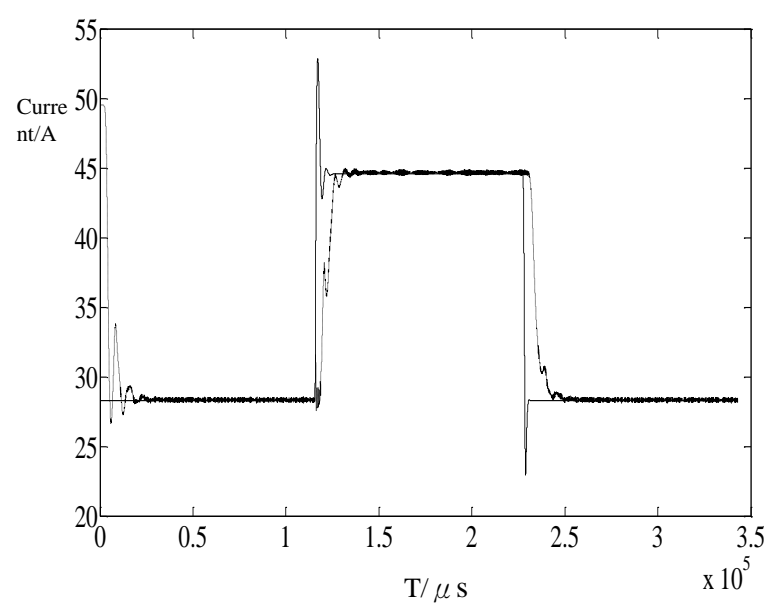

Fig. 7. The comparison chart of current.

\section{CONCLUSION}

From the experiment and simulation, regardless of the 
faults, virtual short-circuit current can always guarantee to equal with the rotating machine output current. Therefore, the relay protection scheme of frequency conversion proposed in this paper successfully solves the problem of output-current limitation. The inverter can provide useful fault information for the relay protection. Because of it, traditional relay protection methods can still be applied in the micro-grid.

\section{REFERENCES}

[1] B. H. Kostova, Z. Styczynski, and R. Krebs, "New protection concepts for distribution systems with dispersed generation," Power Tech 2005 IEEE, Russia, pp. 1-6, 2005.

[2] M T. Doyle, "Reviewing the impacts of distributed generation on distribution system protection," in Proc. IEEE Power Engineering Society Summer Meeting, 2002, vol. 1, pp. 103-105.

[3] N. S. Nafi, K. Ahmed, M. Datta et al., "A novel Zigbee based pilot protection scheme for smart distribution grid," in Proc. the Telecommunication Networks and Applications Conference (ATNAC) IEEE, Australasian, 2014, pp. 146-151.

[4] G. Zou, H. Gao, B. Tong et al., "Directional pilot protection method for distribution grid with DG," in Proc. the Developments in Power System Protection (DPSP 2014), 12th IET International Conference on IET, 2014, pp. 1-5.

[5] H. A. Nasseri and M. A. Redfern, "Harmonics content based protection scheme for micro-grids dominated by solid state converters," in Proc. the Power System Conference, MEPCON 2008, 12th International Middle-East IEEE, 2008, pp. 50-56.

[6] R. Huang, "Research on micro-grid protection of the bidirectional blocking protection which makes use of the failure message with direction information," Chongqing University, 2010.

[7] K. R. Krishnanand and P. K. Dash, "A new real-time fast discrete S-transform for cross-differential protection of shunt-compensated power systems," IEEE Transactions on Power Delivery, vol. 28, no. 1 , pp. 402-410, 2013.

[8] M. O. Oliveira, G. D. Ferreira, F. H. Garcia et al., "Adaptive differential protection for power transformer based on transient signal analysis," in Proc. 2012 IEEE Power and Energy Society General Meeting, 2012, pp. 1-7.

[9] W. P. Wang, Z. Pan, W. Cong et al., "Impact of Distributed Generation on relay protection and its improved Measures," in Proc. IEEE 2008 China International Conference on the Electricity Distribution, 2008, pp. 1-5.

[10] N. Eghtedarpour and E. Farjah, "Distributed charge/discharge control of energy storages in a renewable-energy-based DC micro-grid," Renewable Power Generation, IET, vol. 8, no. 1, pp. 45-57, 2014

[11] J. Li, J. A. Momoh, and S. S. Reddy, "Prony analysis of damping characteristic for micro-grid with energy storage system," in Proc. IEEE North American Power Symposium (NAPS), 2014, pp. 1-4.
[12] B. W. Min, K. H. Jung, M. S. Choi et al., Agent-Based Adaptive Protection Coordination in Power Distribution Systems, 2003.

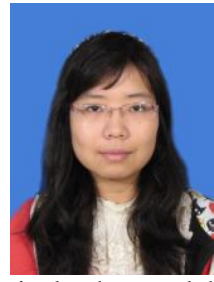

Yifei Xu was born on October 10, 1990 in Nanjing, China. She is now a graduate student in Zhejiang University, Hangzhou, China. She received the B.S degree from Hohai University, Nanjing, China, in 2013.

Her major is electrical engineering and her research field is the application of power electronics in electric power system. Her research also interests include the micro-grid application, distributed generation and single-phase and three-phase dc/ac inverter.

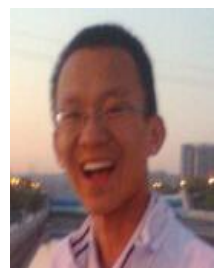

Huan Ma was born on November 15, 1990 in China $\mathrm{He}$ is now working in East China Tongbai Pumped Storage Power Co., Ltd., State Grid Xinyuan Company. He received the B.S degree from Hohai University, Nanjing, China, in 2013.

His major research is on distributed generation, renewable energy conversion and resonant power conversion. He has relevant practical experience on the field of distributed generation.

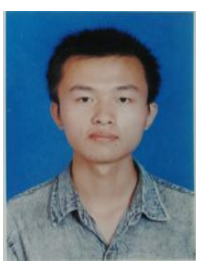

Jiao He was born on March 12, 1989 in China. He is graduate student in Zhejiang University.

His major is electrical engineering. He received the B.S. degree in electrical engineering from Zhejiang University, Zhejiang, China, in 2012.

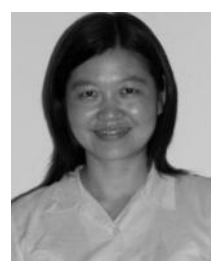

Dehua Zhang was born in China. She received the B.S., M.S., and Ph.D. degree in electrical engineering from Zhejiang University, Zhejiang, China, in 1993 , 1996, and 2002, respectively.

She is an associate professor in the College of Electrical Engineering, Zhejiang University. In 2011 she joined the Department of Electrical Engineering, University of Central Florida, and Orlando, as a research scholar. Her research interests include the application of power electronics, digital control in power electronics and sof switch inverter. She has authored and co-authored more than 30 technical papers published in journals and conference proceedings. 